\title{
Can a New Scoring System Improve Prediction of Pulmonary Hypertension in Newly Recognised Interstitial Lung Diseases?
}

\author{
Małgorzata Sobiecka ${ }^{1}$ (1) Katarzyna Lewandowska ${ }^{1} \cdot$ Jarosław Kober $^{2} \cdot$ Monika Franczuk $^{3} \cdot$ Agnieszka Skoczylas $^{4}$. \\ Witold Tomkowski ${ }^{1} \cdot$ Jan Kuś ${ }^{1} \cdot$ Monika Szturmowicz ${ }^{1}$
}

Received: 30 November 2019 / Accepted: 12 March 2020 / Published online: 23 March 2020

(C) The Author(s) 2020

\begin{abstract}
Introduction Pulmonary hypertension (PH) is a well-recognised complication of interstitial lung diseases (ILD), which worsens prognosis and impairs exercise capacity. Echocardiography is the most widely used, non-invasive method for PH assessment. The aim of our study was to identify the factors predictive for echocardiographic signs of PH in newly recognised ILD patients.

Methods Ninety-three consecutive patients (28F/65M) with different ILD were prospectively evaluated from January 2009 to March 2014. Pulmonary function testing, 6-min walk distance (6MWD), initial and sixth minute room air oxygen saturation, NT-proBNP and echocardiography were assessed in each patient. Echocardiographic PH probability was determined according to the 2009 ESC/ERS guidelines.

Results In 41 patients (Group B) increased PH possibility has been diagnosed on echocardiography, in 52 patients (Group A)—low PH probability. Most pronounced differences $(p \leq 0.0005)$ between groups B and A concerned: age, $6 \mathrm{MWD}$, room air oxygen saturation at $6 \mathrm{~min}$, DLCO and TLC/DLCO index (57.6 vs 43.8 years; 478 vs $583 \mathrm{~m}$; 89.1\% vs $93.4 \%$; 54.8\% predicted vs $70.5 \%$ predicted and 1.86 vs 1.44 ; respectively). Univariate analysis showed four-fold increased probability of $\mathrm{PH}$ when TLC/DLCO exceeded 1.67. A scoring system incorporating age, TLC/DLCO index, 6MWD and room air oxygen saturation at 6 min provided high diagnostic utility, AUC 0.867 (95\% CI 0.792-0.867).

Conclusion ILD patients with TLC/DLCO index $>1.67$ have a high likelihood of $\mathrm{PH}$ and should undergo further evaluation. The composite model of $\mathrm{PH}$ prediction, including age, 6-min walk test and TLC/DLCO was highly specific for recognition of $\mathrm{PH}$ on echocardiography.
\end{abstract}

Keywords Interstitial lung disease · Pulmonary hypertension · Total lung capacity · Diffusion capacity for carbon monoxide $\cdot$ NT-proBNP

Małgorzata Sobiecka

m.sobiecka@igichp.edu.pl

1 1st Department of Lung Diseases, National Tuberculosis and Lung Diseases Research Institute, Plocka 26, 01-138 Warsaw, Poland

2 Department of Radiology, National Tuberculosis and Lung Diseases Research Institute, Warsaw, Poland

3 Department of Respiratory Physiopathology, National Tuberculosis and Lung Diseases Research Institute, Warsaw, Poland

4 Department of Geriatrics, National Institute of Geriatrics, Rheumatology and Rehabilitation, Warsaw, Poland

\section{Introduction}

Interstitial lung disease (ILD) encompasses a large heterogeneous group of inflammatory and fibrotic lung diseases. Chronic fibrosing ILD, such as idiopathic pulmonary fibrosis (IPF), chronic hypersensitivity pneumonitis, nonspecific interstitial pneumonia (NSIP), and sarcoidosis are the most common entities in this group of disorders $[1,2]$. Pulmonary hypertension $(\mathrm{PH})$ is a well-recognised complication of several ILDs, worsening prognosis and impairing exercise capacity [3-8]. Among patients with ILD, PH has been most often studied in IPF, sarcoidosis and hypersensitivity pneumonitis [9-11]. The prevalence of PH ranges from 8 up to $86 \%$ in patients with IPF, and from 6 up to $74 \%$ in patients with sarcoidosis-depending 
on the diagnostic algorithm, the $\mathrm{PH}$ definition, the stage and severity of the underlying disease [4, 12-15].

Despite increasing awareness of $\mathrm{PH}$, diagnosis is often delayed due to common symptoms of PH and ILD, such as shortness of breath and exercise limitation [16]. Furthermore, PH may also occur in non-hypoxemic patients with mild-to-moderate functional impairment and in sarcoidosis-in patients without evident features of interstitial lung disease $[5,17]$. As the presence of $\mathrm{PH}$ is the known marker of poor prognosis in ILD, it seems necessary to stratify patients and identify those who need assessment for $\mathrm{PH}$. Moreover, early recognition of $\mathrm{PH}$ in patients with ILD may be important, in terms of planning diagnostic tests (higher risk of bleeding during lung biopsies in case of $\mathrm{PH}$ ), establishing an indication for long-term oxygen therapy in hypoxemic patients and considering qualification for lung transplantation [18].

Right heart catheterisation is the gold standard for the diagnostic confirmation of $\mathrm{PH}$. Nevertheless, it is not recommended as a routine screening tool in patients with lung diseases because it is an invasive procedure [19]. Right heart catheterisation is currently recommended for the diagnosis of group $3 \mathrm{PH}$ only in selected circumstances, such as listing for lung transplantation, suspicion of pulmonary arterial hypertension or chronic thromboembolic $\mathrm{PH}$ and considering $\mathrm{PH}$-directed therapy in randomised clinical trials [20].

Echocardiography is the most widely used and recommended non-invasive method for PH assessment [20]. Screening for PH with echocardiography should be applied in patients with clinical data suggestive of increased risk of this complication. Unfortunately, the optimal method of qualification of ILD patients for echocardiography has not been established.

Some authors suggest that elevated forced vital capacity to diffusing lung capacity for carbon monoxide (FVC/ DLCO) ratio may be a useful, non-invasive prognostic marker for PH in patients with IPF and systemic sclerosis [21-23]. However, there are various situations that may alter the FVC (e.g. emphysema combined with lung fibrosis, obstructive disorders), and the utility of measuring this ratio as a screening tool might be reduced [24]. The assessment of total lung capacity (TLC) is the gold standard for detecting a restrictive pattern, and it is a part of routine diagnostic work-up of patients with ILD, as well as patients with PH reported to international registers [25]. It was found that only about $60 \%$ of those with a restrictive spirometric pattern defined as $\mathrm{FVC}<80 \%$ predicted and $\mathrm{FEV}_{1} / \mathrm{FVC}>0.7$ before bronchodilatation, have a true restrictive impairment of lung function defined as a TLC below the lower limit of normal [26]. In addition, TLC has been shown to be significantly associated with mortality in patients with group $3 \mathrm{PH}$ [27] and in an unselected population of elderly patients [28].
Therefore, the aim of the present prospective study was to assess whether a new non-invasive ratio, plethysmographic TLC\% predicted divided by corrected for haemoglobin DLCO $\%$ predicted (TLC/DLCO) can provide useful information for screening $\mathrm{PH}$ in patients with newly recognised ILD and to create the scoring system for prediction of PH assessed by echocardiography.

\section{Materials and Methods}

\section{Patient Population}

All consecutive patients presented to a single pulmonary department between 2009 and 2014, diagnosed with various ILD, according to the current at that time guidelines [29-31], entered the study.

The exclusion criteria were: age $<18$ years, significant left heart disease, acute pulmonary embolism or chronic thromboembolic PH, severe renal or liver insufficiency and the presence of severe comorbidities with poor prognosis (e.g. cancer, severe neurological disease). The patients with a known diagnosis of connective tissue disease-ILD were also excluded due to possibility of pulmonary arterial hypertension in this group.

\section{Procedures}

2D-Doppler echocardiographic transthoracic examination was performed with Siemens Accusuin, Sequoia, and Toshiba Medical Systems SSH-880 CV/W1 Artida, as a part of the initial evaluation. Arbitrary criteria of $\mathrm{PH}$ were adopted according to the 2009 ESC/ERS guidelines (Table 1) [32].

Computed tomography of the chest was performed with Somaton Sensation 16.

Exercise capacity was assessed with a 6 min walk test (6MWT) performed on a corridor in accordance with ATS guidelines [33]. Distance covered during 6 min of walking (6MWD), as well as baseline (sat 0 ) and sixth minute (sat 6) room air oxygen saturation were noted.

All pulmonary function measurements were performed with the use of an integrated measuring device MasterScreen Body/Diffusion by Jaeger (Germany 2002), following the ERS/ATS recommendations [34]. The values of pulmonary function indices were reported as a percentage of the predicted values according to ERS reference equations [35], and Falaschetti [36] for FEV ${ }_{1}$ and FVC values. The measurements of diffusing lung capacity for carbon monoxide (DLCO) were performed by the single breath method, with helium gas as a marker, according to ERS standards [37]. The results were presented as a percentage of the predicted values with correction for haemoglobin. 
Table 1 Arbitrary echocardiographic criteria for estimating the presence of pulmonary hypertension $(\mathrm{PH})$ according to ERS/ESC 2009 [32]

\begin{tabular}{llll}
\hline TRV max & PASP & $\begin{array}{l}\text { Additional echocardiographic vari- } \\
\text { ables suggestive of PH* }\end{array}$ & $\begin{array}{l}\text { Echocardio- } \\
\text { graphic probabil- } \\
\text { ity of PH }\end{array}$ \\
\hline$\leq 2.8 \mathrm{~m} / \mathrm{s}$ & $\leq 36 \mathrm{mmHg}$ & Absent & Unlikely \\
$\leq 2.8 \mathrm{~m} / \mathrm{s}$ & $\leq 36 \mathrm{mmHg}$ & Present & Possible \\
$2.9-3.4 \mathrm{~m} / \mathrm{s}$ & $37-50 \mathrm{mmHg}$ & Absent or present & Likely \\
$>3.4 \mathrm{~m} / \mathrm{s}$ & $>50 \mathrm{mmHg}$ & Absent or present & \\
\hline
\end{tabular}

$P A S P$ pulmonary arterial systolic pressure, $P H$ pulmonary hypertension, $T R V$ tricuspid regurgitant velocity *Increased velocity of pulmonary valve regurgitation, short right ventricular outflow acceleration time, increased right heart chambers, increased right ventricular wall thickness, flattening or paradoxical movement of interventricular septum
Serum N-terminal pro-B-type natriuretic peptide (NTproBNP) in venous blood samples was analysed at the hospital's accredited laboratory, using a standard procedure (Elecsys proBNP II, Cobas e411, Roche Diagnostics GmbH, Germany). The upper limit of normal range was $125 \mathrm{pg} / \mathrm{ml}$.

\section{Statistical Analysis}

All analyses were performed with R-a software environment for statistical computing and graphics (https://www.r-proje ct.org/) [38]. Continuous variables were presented as means and standard deviations, and categorical ones-as percentages of the entire population studied. Distributions' normality and homogeneity of variance of continuous variables in groups with different $\mathrm{PH}$ probability were checked with Shapiro-Wilk test and $F$ test, respectively. If both criteria were fulfilled, $T$-Student test and otherwise $U$ Mann-Whitney test was used. Categorical variables distribution was compared with Pearson's test with its modifications if applicable. Youden method was used for calculation of cut off values of parameters with the highest specificity and sensitivity for $\mathrm{PH}$ prediction. Regression analysis (odds ratios and 95\% confidence intervals) was applied to assess the PH risk combined with different factors.

\section{Results}

\section{Baseline Characteristics}

The examined group consisted of 93 patients, 65 males, 28 females, mean age $49.9 \pm 13.9$ years. Sarcoidosis was diagnosed in 42 patients (stage I-in 15, II-in 21, III-in 3 and IV-in 3), hypersensitivity pneumonitis-in 22, IPF-in 21, and other types of idiopathic interstitial pneumonia-in 8 patients.

The results of echocardiography revealed a low probability of PH (PH unlikely) in 52 patients, intermediate probability ( $\mathrm{PH}$ possible) - in 38, and high probability ( $\mathrm{PH}$ likely) - in 3. For further analysis, two echocardiographic categories have been defined: group A-low probability of $\mathrm{PH}, 52$ patients (56\%), and group $\mathrm{B}$-increased probability of PH (PH possible and PH likely), 41 patients (44\%). Mean SPAP has been calculated as $29.2 \pm 3.05$ in group A and $38.34 \pm 7.22$ in group B $(p=0.00000001)$.

Mean age, pulmonary function test values, 6MWT parameters and NT-proBNP concentration in both groups are presented in Table 2.

Patients belonging to group B were significantly older compared to those from group A (mean age 57.6 vs 43.8 years, respectively). They covered a significantly shorter distance during 6MWT (478 vs $583 \mathrm{~m}$ ), with significantly lower mean sat 0 (95.8 vs $96.6 \%)$ and mean sat 6 (89.1 vs $93.4 \%$ ) compared to group A. Plethysmography revealed a tendency towards lower TLC in group B compared to those of group A (92 vs $96 \%$ pred.), in spirometry, $\mathrm{FVC}$ and $\mathrm{FEV}_{1} \% \mathrm{FVC}$ were comparable in both groups. Mean DLCO value was significantly lower in group B compared to group A, (54.8 vs $70.5 \%$ pred.; $p=0.0005)$. The average TLC/DLCO index was 1.86 in group B and 1.44 in group $\mathrm{A},(p=0.00001)$.

\section{ROC Analysis}

ROC analysis revealed the highest value of age, $6 \mathrm{MWD}$, sat 6, and TLC/DLCO index, for PH prediction (Table 3). Optimal specificity and sensitivity were calculated for subsequent cut off values: age $>53$ years, $6 \mathrm{MWD}<507.5 \mathrm{~m}$, sat $6<93 \%$, and TLC/DLCO ratio $>1.67$ (Table 4).

The ROC curves illustrating the diagnostic utility of age, 6MWD, sat 6 and TLC/DLCO ratio for PH prediction are shown on Fig. 1. The comparison of VC/DLCO, FVC/ DLCO and TLC/DLCO are shown on Fig. 2.

Univariate analysis revealed that the risk of $\mathrm{PH}$ on echocardiography was increased by four times in the patients with TLC/DLCO exceeding 1.67 (Table 5). 
Table 2 Comparison of chosen parameters (means \pm SD) in the groups with different probability of $\mathrm{PH}$ on echocardiography

\begin{tabular}{llll}
\hline Parameter & $\begin{array}{l}\text { Group A (low } \\
\text { PH probabil- } \\
\text { ity) }\end{array}$ & $\begin{array}{l}\text { Group B } \\
\text { (increased PH } \\
\text { probability) }\end{array}$ & $p$ \\
\hline Age (years) & $43.8 \pm 12.2$ & $57.6 \pm 12.1$ & 0.0000006 \\
$\begin{array}{l}\text { Smoking (pack- } \\
\text { years) }\end{array}$ & $6.9 \pm 14.0$ & $17.8 \pm 21.8$ & 0.0043 \\
6MWD (m) & $583.1 \pm 111.6$ & $478.2 \pm 109$ & 0.0000204 \\
Sat 0 (\%) & $96.6 \pm 2.3$ & $95.8 \pm 1.9$ & 0.00227 \\
Sat 6 (\%) & $93.4 \pm 5.2$ & $89.1 \pm 7.0$ & 0.000566 \\
Desaturation (\%) & $3.3 \pm 3.9$ & $6.7 \pm 5.7$ & 0.0013 \\
FEV1\%FVC & $78.5 \pm 6.3$ & $75.8 \pm 9.3$ & 0.1746 \\
FVC (\% pred) & $94.5 \pm 22.7$ & $95.0 \pm 21.3$ & 0.9126 \\
TLC (\% pred) & $96.0 \pm 19.4$ & $91.9 \pm 21.9$ & 0.3524 \\
DLCO (\% pred) & $70.5 \pm 20.8$ & $54.8 \pm 22.2$ & 0.0005 \\
TLC/DLCO & $1.44 \pm 0.6$ & $1.86 \pm 0.6$ & 0.00001 \\
FVC/DLCO & $1.4 \pm 0.45$ & $1.82 \pm 0.67$ & 0.00001 \\
VC/DLCO & $1.43 \pm 0.48$ & $1.94 \pm 0.68$ & 0.00001 \\
NT-proBNP (pg/ml) & $58.4 \pm 53.9$ & $150.7 \pm 300.7$ & 0.019 \\
\hline
\end{tabular}

$D L C O$ diffusion lung capacity for carbon monoxide, $F E V_{1}$ forced expiratory volume in one second, $F V C$ forced vital capacity, $6 M W D$ 6-min walk distance, $N T$-proBNP N-terminal brain natriuretic peptide, $P H$ pulmonary hypertension, Sat $O$ baseline room air oxygen saturation, Sat 6 sixth minute room air oxygen saturation, $T L C$ total lung capacity, $T L C / D L C O$ total lung capacity\% predicted/diffusion lung capacity for carbon monoxide corrected for haemoglobin $\%$ predicted, FVC/DLCO forced vital capacity \%predicted/diffusion lung capacity for carbon monoxide corrected for haemoglobin $\%$ predicted, $V C / D L C O$ vital capacity \%predicted/diffusion lung capacity for carbon monoxide corrected for haemoglobin \% predicted

\section{PH-Prediction Scoring Model}

A scoring system for prediction of $\mathrm{PH}$ assessed by echocardiography has been created. The parameters exceeding optimal cut off values have been scored according to the results of ROC analysis: age $>53$ years and TLC/DLCO $>1.67$, three points each, $6 \mathrm{MWD}<507.5 \mathrm{~m}$ and sat $6<93 \%$ - two points each (maximal score-10 points). The AUC of the scoring model for PH prediction was 0.867 (95\% CI 0.792-0.867). Optimal cut off score, indicating the increased probability of PH was 6 points, the specificity, sensitivity, positive predictive value and negative predictive values were: $94 \%, 66 \%$, $90 \%$ and $78 \%$, respectively. ROC curves for $\mathrm{PH}$ prediction according to scoring results are shown on Fig. $3 \mathrm{a}$ and $\mathrm{b}$.

\section{Discussion}

This is the first report on TLC/DLCO ratio as a predictive marker for PH in newly diagnosed patients with various nonconnective tissue disease-ILD. Moreover, a simple scoring system consisting of age, TLC/DLCO ratio, 6-min room air
Table 3 PH prediction: diagnostic utility of various parameters (ROC analysis)

\begin{tabular}{llll}
\hline Parameter & AUC & $95 \%$ CI & $p$ \\
\hline Age (years) & 0.803 & $0.707-0.803$ & 0.000033 \\
Pack-years & 0.665 & $0.555-0.665$ & 0.03 \\
6MWD (m) & 0.761 & $0.663-0.761$ & 0.0002 \\
Sat 0 (\%) & 0.683 & $0.570-0.680$ & 0.02 \\
Sat 6 (\%) & 0.710 & $0.600-0.710$ & 0.005 \\
Desaturation (\%) & 0.696 & $0.585-0.696$ & 0.01 \\
DLCO (\% pred) & 0.710 & $0.602-0.713$ & 0.006 \\
TLC/DLCO & 0.770 & $0.660-0.770$ & 0.0004 \\
FVC/DLCO & 0.77 & $0.675-0.777$ & 0.0069 \\
VC/DLCO & 0.78 & $0.666-0.788$ & 0.0053 \\
NT-proBNP (pg/ml) & 0.645 & $0.528-0.645$ & 0.07 \\
\hline
\end{tabular}

$A U C$ area under curve, $D L C O$ diffusion lung capacity for carbon monoxide, $6 M W D$ 6-min walk distance, $N T$-proBNP N-terminal brain natriuretic peptide, $\mathrm{PH}$ pulmonary hypertension, Sat $\mathrm{O}$ baseline room air oxygen saturation, Sat 6 sixth minute room air oxygen saturation, $T L C / D L C O$ total lung capacity\% predicted/diffusion lung capacity for carbon monoxide corrected for haemoglobin \% predicted, $\mathrm{FVC/}$ $D L C O$ forced vital capacity \%predicted/diffusion lung capacity for carbon monoxide corrected for haemoglobin $\%$ predicted, $V C / D L C O$ vital capacity \%predicted/diffusion lung capacity for carbon monoxide corrected for haemoglobin $\%$ predicted

Table 4 Optimal cut off values of different parameters for PH prediction

\begin{tabular}{llllll}
\hline Parameter & Cut off & Specificity & Sensitivity & PPV & NPV \\
\hline Age (years) & 53 & 0.85 & 0.76 & 0.79 & 0.81 \\
Pack-years & 1.75 & 0.69 & 0.61 & 0.58 & 0.71 \\
6MWD (m) & 507.5 & 0.76 & 0.63 & 0.68 & 0.72 \\
Sat 0 (\%) & 96 & 0.76 & 0.68 & 0.69 & 0.75 \\
Sat 6 (\%) & 93 & 0.75 & 0.65 & 0.67 & 0.73 \\
Desaturation (\%) & 4 & 0.71 & 0.65 & 0.63 & 0.72 \\
DLCO (\% pred) & 68 & 0.67 & 0.78 & 0.65 & 0.79 \\
TLC/DLCO & 1.67 & 0.92 & 0.65 & 0.87 & 0.77 \\
NT-proBNP (pg/ml) & 38 & 0.49 & 0.77 & 0.54 & 0.74 \\
\hline
\end{tabular}

$D L C O$ diffusion lung capacity for carbon monoxide, 6MWD 6-min walk distance, $N T$-proBNP N-terminal brain natriuretic peptide, $P H$ pulmonary hypertension, Sat 0 baseline room air oxygen saturation, Sat 6 sixth minute room air oxygen saturation, TLC/DLCO total lung capacity $\%$ predicted/diffusion lung capacity for carbon monoxide corrected for haemoglobin $\%$ predicted

oxygen saturation and 6MWD was highly specific for the recognition of $\mathrm{PH}$ on echocardiography, with PPV of $90 \%$.

The most substantial difference between the groups with low and increased probability of PH in our study concerned DLCO (mean predicted values were $70.5 \%$ and $54.8 \%$, respectively, $p=0.0005)$. In patients with the increased probability of $\mathrm{PH}$ we observed the disproportionate decrease of DLCO compared to TLC, indicating the possibility of 


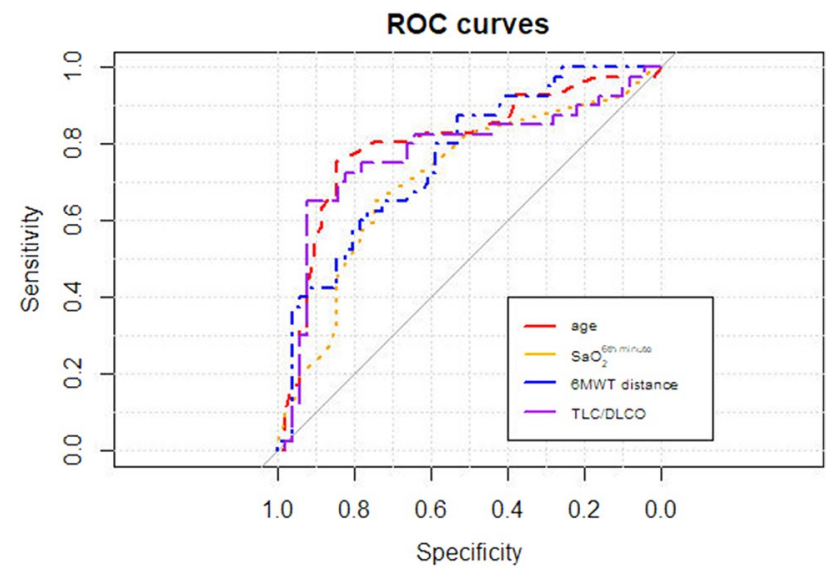

Fig. 1 Diagnostic value of various parameters for $\mathrm{PH}$ prediction (ROC curves)

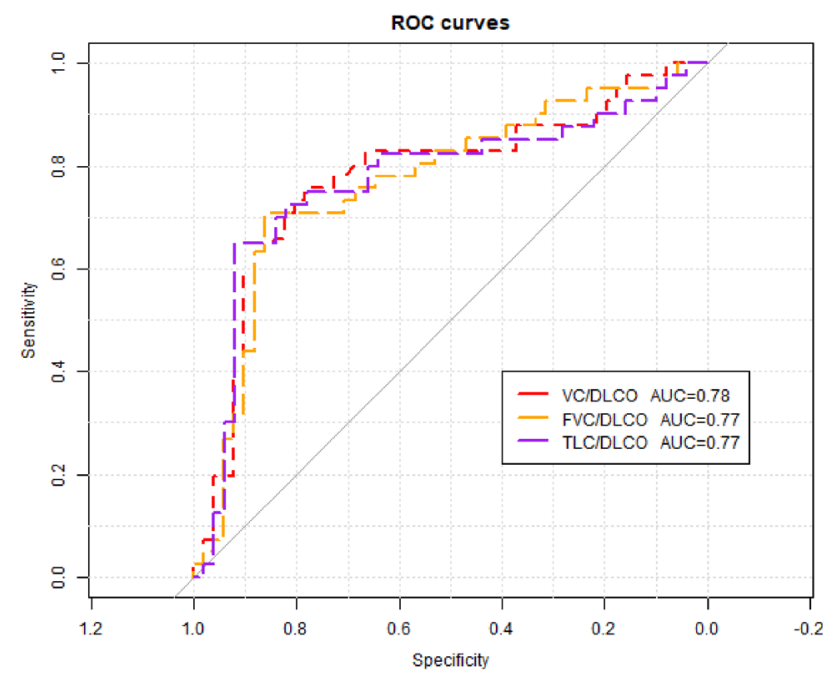

Fig. 2 Comparison of diagnostic values of VC/DLCO, FVC/DLCO and TLC/DLCO for PH prediction (ROC curves)

Table 5 Risk of $\mathrm{PH}$ - univariate analysis

\begin{tabular}{lllll}
\hline Parameter & Cut off & OR & 95\% CI & $p$ \\
\hline Age (years) & 53 & 1.093 & $1.049-1.138$ & 0.000019 \\
Pack-years & 1.75 & 1.036 & $1.008-1.065$ & 0.01 \\
6MWD (m) & 507.6 & 0.991 & $0.987-0.996$ & 0.00016 \\
Sat 6 (\%) & 93 & 0.888 & $0.821-0.961$ & 0.003 \\
Desaturation (\%) & 4 & 1.162 & $1.052-1.284$ & 0.0032 \\
DLCO (\%predicted) & 68 & 0.967 & $0.947-0.987$ & 0.0015 \\
TLC/DLCO & 1.67 & 4.393 & $1.557-12.394$ & 0.0052 \\
NT-proBNP (pg/ml) & 38 & 1.008 & $1.001-1.015$ & 0.0259 \\
\hline
\end{tabular}

$D L C O$ diffusion lung capacity for carbon monoxide, $6 M W D$ 6-min walk distance, NT-proBNP N-terminal brain natriuretic peptide, $P H$ pulmonary hypertension, Sat 6 sixth minute room air oxygen saturation, TLC/DLCO: total lung capacity\% predicted/diffusion lung capacity for carbon monoxide corrected for haemoglobin $\%$ predicted
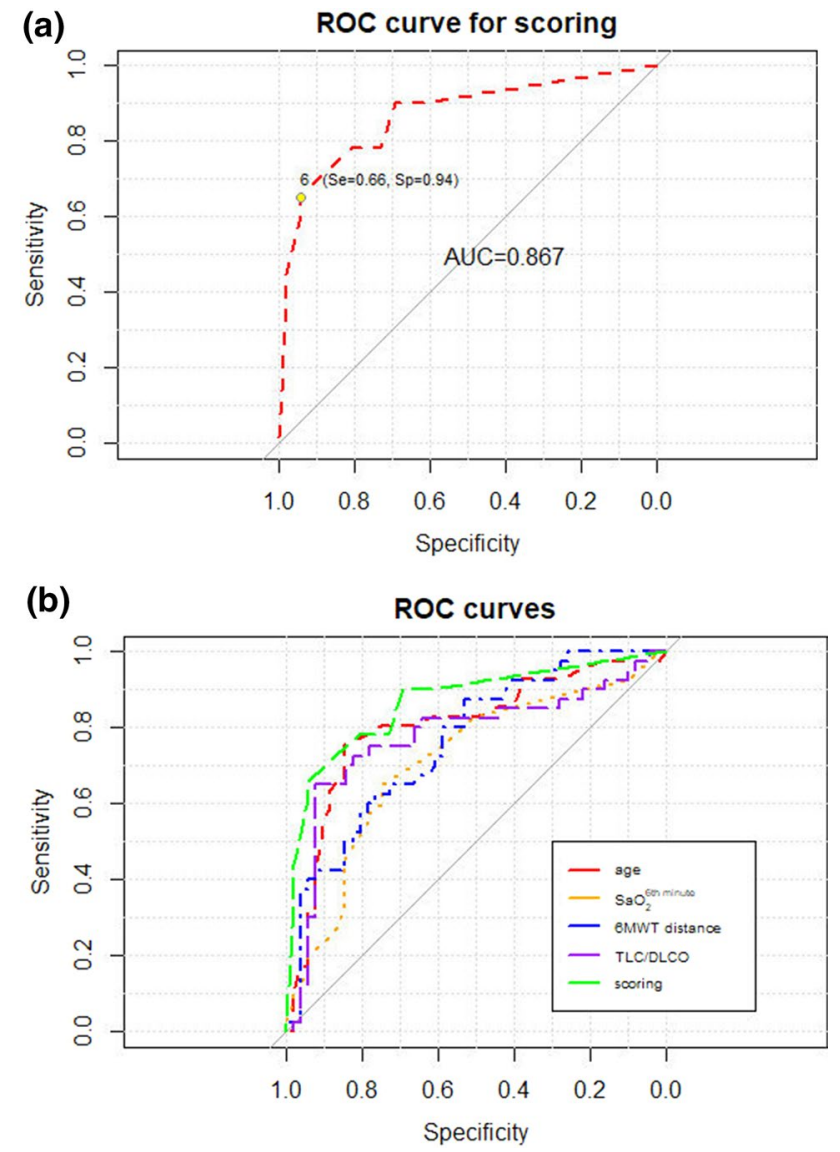

Fig. 3 a and b Diagnostic value of composite model for PH prediction: $\mathbf{a}$ - as a single parameter, $\mathbf{b}$ - in comparison with other predictive factors (ROC curves)

vascular lung disease. This has resulted in significantly higher TLC/DLCO index in group B, compared to group A (1.86 and 1.44, respectively, $p=0.00001)$. Univariate analysis revealed the four-fold increase of $\mathrm{PH}$ probability in the patients with TLC/DLCO ratio exceeding 1.67. TLC/ DLCO $>1.67$ was also the most specific indicator of $\mathrm{PH}$ diagnosed by echocardiography.

The ability to predict PH due to ILD was documented both in sarcoidosis $[39,40]$ and in IPF patients with decreased DLCO [3, 21, 22, 41]. Lettieri et al. found that DLCO $<40 \%$ pred. in the patients with end stage IPF, indicated $\mathrm{PH}$ on right heart catheterisation with $94 \%$ specificity and $65 \%$ sensitivity [3]. In our study, DLCO $<68 \%$ pred. appeared significant for $\mathrm{PH}$ prediction, because the examined group consisted of patients with newly diagnosed ILD, with less severe lung function disturbances.

The other authors applied FVC/DLCO index for PH prediction in patients with IPF $[21,22]$. High diagnostic value of combined FVC/DLCO index and resting room air pulse oximetry has been documented by Zisman et al. [22] and more recently Alkukhun et al. [21]. Therefore, we compared 
diagnostic value of three indexes: FVC/DLCO, VC/DLCO and TLC/DLCO for PH prediction in the present study group. All the three indexes had comparable diagnostic utility. We decided to use TLC/DLCO ratio as the assessment of TLC is the best test to correctly differentiate restrictive from normal lung function. The reduction of TLC is a stronger risk factor for mortality than FVC in an unselected population of elderly patients [28], and it was associated with mortality among patients with group $3 \mathrm{PH}$ [27].

6MWT results showed significantly longer distance in group A compared to group B (583 vs $478 \mathrm{~m}$, respectively). In patients with $\mathrm{PH}$ due to lung diseases, 6MWD is influenced by severity of lung disease, and also by comorbidities and age. Initial and end-walking oxygen saturation during 6MWT may be more valuable $\mathrm{PH}$ predictors than walking distance, especially in ILD patients. Mean sixth minute oxygen saturation was significantly lower in group B compared to group A (89.1\% and $93.4 \%$, respectively). The optimal sixth minute oxygen saturation cut off was $93 \%$ (75\% specificity, $65 \%$ sensitivity). The published data on this subject are contradictory. Lettieri et al. confirmed significantly lower end-walk oxygen saturation in patients with $\mathrm{PH}$ compared to those without $\mathrm{PH}(80 \%$ and $88 \%$, respectively), in end stage IPF patients [3], but Modrykamien et al. did not find the utility of sixth minute oxygen saturation and 6MWD for $\mathrm{PH}$ prediction in IPF [42].

In our group of patients, the mean NT-proBNP serum level was significantly higher in group B compared to group A (151 pg/ml vs $58 \mathrm{pg} / \mathrm{ml})$. Nevertheless, in most patients, NT-proBNP concentrations were within normal limits. Therefore, we conclude that the clinical utility of NTproBNP for $\mathrm{PH}$ prediction in newly diagnosed ILD is low. It seems that low NT-pro BNP at diagnosis may be used as a factor with negative predictive value. Andersen et al. found the concentration $<95 \mathrm{ng} / \mathrm{l}$ excluding $\mathrm{PH}$ on echocardiography in patients with ILD [43].

The composite model of PH prediction, created by our group, consisted of the best single predictors, such as age, TLC/DLCO ratio, sixth minute room air oxygen saturation and 6MWD. The score of 6 points was highly specific for the recognition of $\mathrm{PH}$ on echocardiography (94\%), with PPV of $90 \%$. This is, to our knowledge, the first attempt to create universal scoring system for PH prediction in various ILDs.

The other model of clinical $\mathrm{PH}$ prediction has been presented by Thakhar in scleroderma patients [44]. It was composed of NT-proBNP $\geq 209.8$ and/or DLCO $<70.3 \%$ predicted and FVC/DLCO $\geq 1.82(100 \%$ sensitivity and $77.8 \%$ specificity). Recently, another model of $\mathrm{PH}$ prediction was described by Furukawa et al. in IPF patients [41]. This model included DLCO $<50 \%$, index of pulmonary artery/ descending aorta diameters $>0.9$ and $\mathrm{PaO}_{2}<80 \mathrm{mmHg}$.

There are some limitations of our study. Firstly, as a single tertiary centre study, the ability to avoid data bias was limited. Secondly, the outcome might be influenced by the relatively small number of patients and the heterogeneity of the study population comprised patients with sarcoidosis, hypersensitivity pneumonitis, IPF, and other idiopathic interstitial pneumonias. On the other hand, the included patient population reflects cases encountered in "real-life" clinical practice, and our study aimed to identify easily ascertainable characteristics that would predict the echocardiographic confirmation of PH in newly diagnosed ILD patients. Lastly, our study is limited by the lack of confirmatory right heart catheterization. We used the hemodynamic data obtained by Doppler echocardiography-a noninvasive, inexpensive and widely available method for assessment of PH. Right heart catheterization is not used as a routine screening tool in patients with lung diseases due to its invasiveness, and this method is currently recommended for the diagnosis of group $3 \mathrm{PH}$, solely in selected circumstances [45].

The authors are aware that the applied scoring model for clinical PH probability assessment needs validation. Nevertheless, the preliminary results are auspicious, and worth considering as clinically useful and reliable.

\section{Conclusion}

A simple scoring system comprised age, TLC/DLCO ratio and walking test results (air room oxygen saturation at sixth minute and 6MWD) was highly specific for the recognition of $\mathrm{PH}$ on echocardiography. Moreover, TLC/DLCO ratio alone exceeding 1.67 increased the probability of $\mathrm{PH}$ by four times. This index was also the most specific indicator for $\mathrm{PH}$ diagnosed on echocardiography in patients with ILD and should undergo further evaluation.

Author Contributions MS contributed significantly to the conception and design of the study, acquisition and interpretation of data, and along with MSz draughted the manuscript. KL contributed significantly to the acquisition and interpretation of data, and critically revised article. JKo performed echocardiographic examinations, significantly contributed to the interpretation of data, and revised critically article. MF contributed significantly to the interpretation of data and helped to draught the manuscript. AS performed the statistical analysis and significantly contributed to the interpretation of data and helped to draught of the manuscript. WT contributed significantly to the interpretation of data and critically revised the final version of the manuscript. $\mathrm{JKu}$ contributed significantly to the interpretation of data and critically revised the final version of the manuscript. MSz participated in the conception and design of the study, contributed significantly to the interpretation of data, coordinated the whole team and draughted with MS the manuscript. All authors read and approved the final version of the manuscript.

Funding The study was supported by the National Tuberculosis and Lung Diseases Research Institute as part of the statutory activities Grant Nos. 7.7 and 8.11. 
Data Availability The datasets collected and analysed during the current study are available from the corresponding author on reasonable request.

\section{Compliance with Ethical Standards}

Conflict of interest The authors declare that no significant conflicts of interest exist with any companies/organisations whose products or services may be discussed in this article.

Ethical Approval The study was approved by the Human Ethics Committee of the National Tuberculosis and Lung Diseases Research Institute (Approval No. KE 77/2008) and conducted in accordance with the Declaration of Helsinki. Written and informed consent was obtained from participants before enrolment into the study.

Open Access This article is licensed under a Creative Commons Attribution 4.0 International License, which permits use, sharing, adaptation, distribution and reproduction in any medium or format, as long as you give appropriate credit to the original author(s) and the source, provide a link to the Creative Commons licence, and indicate if changes were made. The images or other third party material in this article are included in the article's Creative Commons licence, unless indicated otherwise in a credit line to the material. If material is not included in the article's Creative Commons licence and your intended use is not permitted by statutory regulation or exceeds the permitted use, you will need to obtain permission directly from the copyright holder. To view a copy of this licence, visit http://creativecommons.org/licenses/by/4.0/.

\section{References}

1. Travis WD, Costabel U, Hansell DM et al (2013) ATS/ERS Committee on idiopathic interstitial pneumonias. An official American Thoracic Society/European Respiratory Society statement: update of the international multidisciplinary classification of the idiopathic interstitial pneumonias. Am J Respir Crit Care Med 188(6):733-748. https://doi.org/10.1164/rccm.201308-1483ST

2. Olson AL, Gifford AH, Inase N, Fernández Pérez ER, Suda T (2018) The epidemiology of idiopathic pulmonary fibrosis and interstitial lung diseases at risk of a progressive-fibrosing phenotype. Eur Respir Rev 27:180077. https://doi.org/10.1183/16000 617.0077-2018

3. Lettieri CJ, Nathan SD, Barnett SD, Ahmad S, Shorr AF (2006) Prevalence and outcomes of pulmonary arterial hypertension in advanced idiopathic pulmonary fibrosis. Chest 129(3):746-752. https://doi.org/10.1378/chest.129.3.746

4. Shorr AF, Helman DL, Davies DB, Nathan SD (2005) Pulmonary hypertension in advanced sarcoidosis: epidemiology and clinical characteristics. Eur Respir J 25(5):783-788. https://doi. org/10.1183/09031936.05.00083404

5. Kimura M, Taniguchi H, Kondoh Y et al (2013) Pulmonary hypertension as a prognostic indicator at the initial evaluation in idiopathic pulmonary fibrosis. Respiration 85:456-463. https://doi. org/10.1159/000345221

6. Mejia M, Carillo G, Rojas-Serrano J et al (2009) Idiopathic pulmonary fibrosis and emphysema. Decreased survival associated with severe pulmonary arterial hypertension. Chest 136(1):10-15. https://doi.org/10.1378/chest.08-2306

7. Koschel DS, Cardoso C, Wiedemann B, Höffken G, Halank M (2012) Pulmonary hypertension in chronic hypersensitivity pneumonitis. Lung 190(3):295-302. https://doi.org/10.1007/s0040 8-011-9361-9

8. Gläser S, Noga O, Koch B et al (2009) Impact of pulmonary hypertension on gas exchange and exercise capacity in patients with pulmonary fibrosis. Respir Med 103(2):317-324. https://doi. org/10.1016/j.rmed.2008.08.005

9. Caminati A, Cassando R, Harari S (2013) Pulmonary hypertension in chronic interstitial lung diseases. Eur Respir Rev 22(129):292301. https://doi.org/10.1183/09059180.00002713

10. Oliveira RKF, Pereira CAC, Ramos RP et al (2014) A hemodynamic study of pulmonary hypertension in chronic hypersensitivity pneumonitis. Eur Respir J 44(2):415-424. https://doi. org/10.1183/09031936.00010414

11. Baughman RP, Shlobin OA, Wells AU et al (2018) Clinical features of sarcoidosis associated pulmonary hypertension: results of a multi-national registry. Respir Med 139:72-78. https://doi. org/10.1016/j.rmed.2018.04.015

12. Hamada K, Nagai S, Tanaka S et al (2007) Significance of pulmonary arterial pressure and diffusion capacity of the lung as prognosticator in patients with idiopathic pulmonary fibrosis. Chest 131(3):650-656. https://doi.org/10.1378/chest.06-1466

13. Nathan SD, Shlobin OA, Ahmad S (2008) Serial development of pulmonary hypertension in patients with idiopathic pulmonary fibrosis. Respiration 76:288-294. https://doi.org/10.1159/00011 4246

14. Shorr AF, Wainright JL, Cors CS, Lettieri CJ, Nathan SD (2007) Pulmonary hypertension in patients with pulmonary fibrosis awaiting lung transplant. Eur Respir J 30(4):715-721. https://doi. org/10.1183/09031936.00107206

15. Rizatto G, Pezzano A, Sala G et al (1983) Right heart impairment in sarcoidosis: haemodynamic and echocardiographic study. Eur J Respir Dis 64(2):121-128

16. Behr J, Ryu JH (2008) Pulmonary hypertension in interstitial lung disease. Eur Respir J 31(6):1357-1367. https://doi. org/10.1183/09031936.00171307

17. Nunes H, Humbert M, Capron F et al (2006) Pulmonary hypertension associated with sarcoidosis: mechanisms, haemodynamics and prognosis. Thorax 61(1):68-74. https://doi.org/10.1136/ thx.2005.042838

18. Szturmowicz M, Kacprzak A, Błasińska-Przerwa K, Kuś J (2015) Pulmonary hypertension in the course of diffuse parenchymal lung diseases - state of art and future considerations. Pneumonol Alergol Pol 83(4):312-323. https://doi.org/10.5603/PiAP.2015.0051

19. Hoeper MM, Lee SH, Voswinckel R et al (2006) Complications of right heart catheterisation procedures in patients with pulmonary hypertension in experienced centers. J Am Coll Cardiol 48(12):2546-2552. https://doi.org/10.1016/j.jacc.2006.07.061

20. Galie N, Humbert M, Vachiery JL et al (2015) 2015 ESC/ERS guidelines for the diagnosis and treatment of pulmonary hypertension. Eur Respir J 46(4):903-975. https://doi.org/10.1183/13993 003.01032-2015

21. Alkukhun L, Wang X-F, Ahmed MK et al (2016) Non-invasive screening for pulmonary hypertension in idiopathic pulmonary fibrosis. Respir Med 117:65-72. https://doi.org/10.1016/j. rmed.2016.06.001

22. Zisman DA, Karlamangla AS, Kawut SM et al (2008) Validation of a method to screen for pulmonary hypertension in advanced idiopathic pulmonary fibrosis. Chest 133(3):640-645. https://doi. org/10.1378/chest.07-2488

23. Coghlan JG, Denton CP, Grünig E et al (2014) Evidence-based detection of pulmonary arterial hypertension in systemic sclerosis: the DETECT study. Ann Rheum Dis 73(7):1340-1349. https://doi. org/10.1136/annrheumdis-2013-203301

24. Antoniou KM, Margaritopoulos GA, Goh NS et al (2016) Combined pulmonary fibrosis and emphysema in scleroderma lung disease has a major confounding effect on lung physiology and 
screening for pulmonary hypertension. Arthritis Rheumatol 68:1004-1012. https://doi.org/10.1002/art.39528

25. Hoeper MM, Behr J, Held M et al (2015) Pulmonary hypertension in patients with chronic fibrosing idiopathic interstitial pneumonias. PLoS ONE 10(12):e0141911. https://doi.org/10.1371/journ al.pone.0141911

26. Aaron SD, Dales RE, Cardinal P (1999) How accurate is spirometry at predicting restrictive pulmonary impairment. Chest 115(3):869-973. https://doi.org/10.1378/chest.115.3.869

27. Chebib N, Mornex J-F, Traclet J et al (2018) Pulmonary hypertension in chronic lung diseases: comparison to other pulmonary hypertension groups. Pulm Circ 8(2):1-10. https://doi. org/10.1177/2045894018775056

28. Pedone C, Scarlata S, Chiurco D, Conte ME, Forastiere F, Antonelli-Incalzi R (2012) Association of reduced total lung capacity with mortality and use of health services. Chest 141(4):1025-1030. https://doi.org/10.1378/chest.11-0899

29. Statement on sarcoidosis (1999) Joint statement of the American Thoracic Society (ATS), the European Respiratory Society (ERS) and the World Association of Sarcoidosis and Other Granulomatous Disorders (WASOG) adopted by the ATS Board of Directors and by the ERS Executive Committee. Am J Respir Crit Care Med 160(2):736-755. https://doi.org/10.1164/ajrccm.160.2.ats4-99

30. American Thoracic Society/European Respiratory Society (2002) American Thoracic Society/European Respiratory Society international multidisciplinary consensus classification of the idiopathic interstitial pneumonias. Am J Respir Crit Care Med 165:277-304. https://doi.org/10.1164/ajrccm.165.2.ats01

31. Raghu G, Collard HR, Egan JJ et al (2011) An official ATS/ ERS/JRS/ALAT statement: idiopathic pulmonary fibrosis: evidence-based guidelines for diagnosis and management. Am J Respir Crit Care Med 183:788-824. https://doi.org/10.1164/ rccm.2009-040GL

32. Galie N, Hoepper MM, Humbert M et al (2009) Guidelines for the diagnosis and treatment of pulmonary hypertension. Eur Respir $\mathbf{J}$ 34(6):1219-1263. https://doi.org/10.1183/09031936.00139009

33. ATS Committee on Proficiency Standards for Clinical Function Laboratories (2002) ATS statement: Guidelines for six-minute walk test. Am J Respir Crit Care Med 166(1):111-117. https:// doi.org/10.1164/ajrccm.166.1.at1102

34. Pellegrino R, Viegi G, Brusasco V et al (2005) Interpretative strategies for lung function test. Eur Respir J 26:948-968. https://doi. org/10.1183/09031936.05.00035205

35. Quanjer P, Tammeling G, Cotes J, Pedersen O, Peslin R, Yernault J-C (1993) Lung volumes and forced ventilator flows. Report Working party. Standardization of lung function tests. European
Community for Steel and Coal. Eur Respir J 6(suppl 16):5-40. https://doi.org/10.1183/09041950.005s1693

36. Falaschetti E, Laiho J, Primatesta P, Purdon S (2004) Prediction equations for normal and low lung function from the Health Survey for England. Eur Respir J 23(3):456-463. https://doi. org/10.1183/09031936.04.00055204

37. Macintyre N, Crapo RO, Viegi G et al (2005) Standardization of the single-breath determination of carbon monoxide uptake in the lung. Eur Respir J 26:720-735. https://doi.org/10.1183/09031 936.05.00034905

38. R core team (2016) R: a language and environment for statistical computing. R Foundation for Statistical Computing, Vienna, Austria. https://www.R-project.org/

39. Bourbonnais JM, Samavati L (2008) Clinical predictors of pulmonary hypertension in sarcoidosis. Eur Respir J 32(2):296-302. https://doi.org/10.1183/09031936.00175907

40. Shlobin OA, Baughman RP (2017) Sarcoidosis-associated pulmonary hypertension. Semin Respir Crit Care Med 38(4):450-462. https://doi.org/10.1055/s-0037-1603767

41. Furukawa T, Kondoh Y, Taniguchi $\mathrm{H}$ et al (2018) A scoring system to predict the elevation of mean pulmonary arterial pressure in idiopathic pulmonary fibrosis. Eur Respir J 51(1):1701311. https://doi.org/10.1183/13993003.01311-2017

42. Modrykamien AM, Gudavalli R, McCarthy K, Parambil J (2010) Echocardiography, 6-minute walk distance, and distance-saturation product as predictors of pulmonary arterial hypertension in idiopathic pulmonary fibrosis. Respir Care 55:584-588

43. Andersen CH, Mellemkjær S, Hilberg O, Bendstrup E (2016) NT-proBNP $<95 \mathrm{ng} / \mathrm{l}$ can exclude pulmonary hypertension on echocardiography at diagnostic workup in patients with interstitial lung disease. Eur Clin Respir J 3:32027. https://doi.org/10.3402/ ecrj.v3.32027

44. Thakkar V, Stevens WM, Prior D et al (2012) N-terminal probrain natriuretic peptide in a novel screening algorithm for pulmonary arterial hypertension in systemic sclerosis: a case-control study. Arthr Res Ther 14(3):R143. https://doi.org/10.1186/ar3876

45. Nathan SD, Barbera JA, Gaine SP et al (2019) Pulmonary hypertension in chronic lung disease and hypoxia. Eur Respir J 53:1801914. https://doi.org/10.1183/13993003.01914-2018

Publisher's Note Springer Nature remains neutral with regard to jurisdictional claims in published maps and institutional affiliations. 